\title{
ESPECULAR LA MIRADA: EDUCAR JÓVENES EN SITUACIONES EXCEPCIONALES ${ }^{1}$
}

\author{
REFLECT THE GAZE: EDUCATING YOUNG PEOPLE IN EXCEPTIONAL SITUATIONS
}

\author{
Analía Umpierrez \\ Universidad Nacional del Centro de Buenos Aires - FLACSO, Argentina \\ aumpierr@soc.unicen.edu.ar
}

Recibido: 31 de julio de 2021

Aprobado: 3 de octubre de 2021

Publicado: 31 de diciembre de 2021

Cita sugerida: Umpierrez, A. (2022). Especular la mirada: educar jóvenes en situaciones excepcionales. Revista de la Escuela de Ciencias de la Educación 1(17), 48-60.

\section{RESUMEN}

Especular la mirada invita a cambiar el foco de quien mira a los y las adolescentes y jóvenes en conflicto con la ley penal y mirar como reflejo en un espejo, a quien los mira desde la escolaridad. Se identifican diferentes planos de concreción de las políticas de protección de niñeces y juventudes y educativas en particular revisando el ámbito institucional, la formación de docentes y las prácticas educativas. Desde allí, revisar la tarea de las instituciones educativas y los educadores en este escenario para reconocer desafíos y algunos caminos en pos de construir colectivamente oportunidades de transformación. Se reconoce que el foco de las intervenciones proactivas debería estar puesto en ajustar la vinculación entre lo que se prescribe y lo que sucede en el territorio, para avanzar en mayores y mejores oportunidades y acceso a derechos de los y las adolescentes y jóvenes en conflicto con la ley penal.

Palabras clave: Instituciones educativas - Prácticas docentes - Contextos de privación de libertad - Formación docente - Derechos humanos.

\section{ABSTRACT}

Reflect the gaze invites us to change the focus of those who look at adolescents and young people in conflict with criminal law and to look as a reflection in a mirror, at those who look at them from school. Different planes of concretion of

\footnotetext{
${ }^{1}$ Este trabajo es una versión revisada de la conferencia homónima ofrecida en el "Seminario virtual Nacional de Educación Inclusiva: Una respuesta efectiva a la diversidad". Ministerio de Educación del Ecuador. Diciembre 2020.
} 
the policies for the protection of children and youth and education are identified, in particular, by reviewing the institutional environment, teacher training and educational practices. From there, review the task of educational institutions and educators in this scenario to recognize challenges and some paths in order to collectively build opportunities for transformation. It is recognized that the focus of proactive interventions should be placed on adjusting the link between what is prescribed and what happens in the territory, to advance greater and better opportunities and access to rights of adolescents and young people in conflict with criminal law.

Keywords: Educational institutions - Teaching practices - Contexts of deprivation of liberty - Teacher training - Human rights.

\section{INTRODUCCIÓN}

La siguiente exposición surge de revisar y organizar algunas reflexiones y resultados fruto de las tareas de docencia, investigación, extensión y gestión que vengo desarrollando en los últimos veinte años y recupera aportes de trabajos de investigación sobre formación de docentes (2009), inclusión y exclusión educativa (2017) y trabajos de investigación sobre la educación en contextos de privación de libertad $(2016,2020)^{2}$.

Se propone aquí una breve contextualización del marco legal y condiciones de la vida cotidiana en centros de detención para jóvenes en conflicto con la ley penal en Argentina como marco y punto de partida para ubicar el eje de la presentación. Se invita a cambiar el foco de la mirada para detenernos en el reflejo en espejo de la detención y mirar a quien mira a los adolescentes y jóvenes desde la escolaridad. Desde allí, revisar la tarea de las instituciones educativas y los educadores ${ }^{3}$ en este escenario para reconocer desafíos y algunos caminos para construir colectivamente oportunidades de transformación.

Antes de comenzar el recorrido, quisiera detenerme en el título propuesto: "Especular la mirada: educar jóvenes en situaciones excepcionales" y esa excepcionalidad en este caso nos ubica en contextos de privación de libertad ambulatoria.

Significar ese "especular la mirada" desde las definiciones que el término invoca ${ }^{4}$ es una invitación a ver y a interrogarnos sobre lo que pasa en las aulas (y de modo particular en los espacios de encierro de adolescentes y jóvenes) y desde allí observar a las instituciones educativas y a las prácticas docentes para

\footnotetext{
2 Este trabajo está enmarcado en el Proyecto de investigación "Formación de docentes en territorio: biografías, prácticas e intervención social" 2019/21- NACT Investigaciones en Formación Inicial y Prácticas Educativas - IFIPRAC-Ed Facultad de Ciencias Sociales (FACSO) UNICEN. Programa de Incentivos. Secat. UNICEN. Se hace referencia además a reflexiones y materiales relevados desde las tareas desarrolladas por la autora en los Programas: "Educación en contextos de encierro" FACSO y "Universidad en la cárcel" dependiente de la Secretaría de Extensión, ambos de la UNICEN.

${ }^{3}$ Se reconoce que el uso del masculino pretendidamente universal opaca la construcción sexogenérica hegemónica, no obstante, se decide mantenerlo con el único fin de ofrecer una lectura más fluida. Toda vez que se haga esta referencia debe incluirse a mujeres y disidencias. ${ }^{4}$ Las acepciones son tomadas del diccionario de la Real Academia Española.
} 
aguzar los sentidos respecto de los modos en que se configuran los procesos de trabajo, las relaciones vinculares, de poder, entre otras.

En realidad, lo que me interesa aquí no es tanto hablar de los jóvenes en contexto de privación de libertad, aunque es un tema muy importante analizar quiénes son, qué hacen, por qué llegan, cuáles son las condiciones de la detención, no es el objetivo central de esta presentación. Pero sí vale la pena antes de avanzar, cuestionar de manera explícita la noción de modo corriente de mencionarlos, como "jóvenes en conflicto con la ley penal". Si bien se trata de una forma discursiva marcada por la Justicia y que es utilizada habitualmente, merece ser tensionada, desnaturalizada, preguntándonos por qué esos jóvenes están "tocados" por la ley, por qué se da ese conflicto con la Ley. Y podríamos avanzar en esta presentación reconociendo como trasfondo el orden social vigente -incluyo aquí a las sociedades capitalistas- no se han generado las condiciones de posibilidad para que estos adolescentes y jóvenes (los hijos de esta sociedad en su totalidad) puedan desarrollar una vida digna desde la perspectiva de los derechos humanos.

Entonces, ¿por qué especular la mirada? Me interesaba, en principio, mirar a estos jóvenes y reconocerlos como quienes nos miran. Es decir, reflejar esa mirada y vernos a nosotros mismos y ver a las instituciones educativas que están situadas en el contexto de la privación de la libertad. Si vamos a mirar ese reflejo, vale la pena repasar de modo muy somero, quiénes son esos que están del otro lado.

En este recorrido entonces, y en primer término, una de las cuestiones que me parece central recuperar en el marco de lo que pasa en Argentina es que, de los jóvenes que están detenidos, presos -no se usa la palabra "presos" sino que están en instituciones cerradas, aunque son claramente espacios similares a las cárceles- más de la mitad se encuentra con medidas privativas de libertad, contradiciendo la prescripción del marco legal vigente que prioriza las medidas de cuidado de niñeces y juventudes.

En una segunda instancia, propongo interrogarnos acerca de las tareas de las instituciones educativas que se localizan al interior de estos espacios y las que forman docentes. Ubicados allí nos preguntamos ¿qué pasa con las prácticas educativas de quienes transitamos por esas aulas? Por otro lado, quienes nos ocupamos de la formación de los educadores ¿tenemos como referencia los espacios de detención como espacios laborales? ¿Identificamos esos territorios específicos, advirtiendo la relevancia de la tarea educativa en sentido amplio? Estos interrogantes nos remiten a revisar al menos dos ejes. Por un lado, para analizar las instituciones educativas y por otro, pensar las prácticas educativas promovidas por personal docente.

\section{DESARROLLO}

\section{Adolescentes y jóvenes, cadena punitiva y encierro}

Una de las primeras consideraciones que deben realizarse en relación a la situación de jóvenes, restricción y privación de libertad en Argentina, es la falta de datos sistematizados, organizados respecto de esta temática (López y Moto, 2017). La segunda consideración es el carácter disperso de la información. A 
partir de lo que es posible localizar, se releva en especial aquella zona en la que se concentra un grueso de la población del país: Ciudad Autónoma de Buenos Aires (CABA) y Provincia de Buenos Aires (PBA). Además, es en esos distritos adonde se concentran mayormente las sedes centrales de los organismos que monitorean estos espacios y los organismos responsables de la temática dependientes del Estado. Del resto del país, y aquello que no aparece contabilizado desde el sistema federal, no ingresa a estadísticas, informes y monitoreo. Esto da cuenta de un centralismo y una mirada acotada que pretende explicar la realidad del país desde la metrópoli y desde la condensación y concentración de problemas.

En Argentina las políticas referidas a la temática de infancia y adolescencia han tenido un cambio de abordaje cuyo hito fue en el año 2005, la sanción de la Ley $n^{\circ}$. 26.061 de Protección Integral de los Derechos de las Niñas, Niños y Adolescentes.

Esta Ley protege de manera integral los derechos de las niñas, niños y adolescentes que se encuentren en el territorio de la Argentina, para garantizar el ejercicio y disfrute pleno, efectivo y permanente de aquellos reconocidos en el ordenamiento jurídico nacional y en los tratados internacionales (Beloff en Salgado y Fridman, 2015, p. 31) y constituye un marco legal de índole federal que surgió en un contexto nacional.

Por otra parte, esta nueva ley nacional en materia de infancia "ejerció presión sobre aquellas provincias que mantenían aun sus viejas leyes de patronato" (Salgado y Fridman, 2015, p. 31) al tiempo que se constituyó en "ley rectora para ellas, marcando los lineamientos generales sobre políticas de infancia y adolescencia" (Salgado y Fridman, 2015, p. 31). Esta Ley además se ocupa del acceso al derecho a la educación (Art.15, 16 y 17) de niños, niñas y adolescentes a la escuela, la gratuidad y la universalidad de la misma.

Por otro lado, merece señalarse que el marco legal vigente respecto de niños, niñas y jóvenes (en adelante NNyJ) (Régimen Penal de la Minoridad, Ley no. 22.278) fue sancionado durante la última dictadura militar (1976/1983). Entre otras disposiciones, fija la edad mínima de imputación en dieciséis años y otorga facultades extraordinarias a los jueces: por ejemplo, disponer de la libertad de los niños y adolescentes por un tiempo indeterminado para que no entorpezca la investigación o por situación de vulnerabilidad.

En Argentina se entiende por políticas para adolescentes infractores a la acción de gobierno dentro de un sistema de responsabilidad penal juvenil que incluye además la ley de fondo, las leyes de procedimientos y la actuación de los tribunales (UNICEF /MDS 2008).

Desde ese marco legal se indica evitar la institucionalización de los jóvenes que cometen delitos, y si así lo fuera, se expresa que la privación de libertad sea sólo una medida de último recurso y aplicada por el período más breve posible 5 .

\footnotetext{
${ }^{5}$ Art.34: Que la privación de libertad sea sólo una medida de último recurso y que sea aplicada por el período más breve posible, debiendo cumplirse en instituciones específicas para niños, separadas de las de adultos, a cargo de personal especialmente capacitado teniendo en cuenta las necesidades de su edad (Ley $\mathrm{N}^{\circ} 13634$ )
} 
La cadena punitiva (Daroqui y López, 2012) sin embargo, se ha profundizado y sigue haciéndolo en estos últimos diez años: policía, justicia y detención se amplía para sectores vulnerabilizados de la población según registros del Comité Provincial Contra la Tortura6. Los jóvenes imputados de haber cometido un delito son enviados a lugares llamados Centros Cerrados ${ }^{7}$ como parte de un dispositivo penal cuyo objetivo principal es

fomentar la capacidad de los adolescentes de ejercer derechos, respetar los derechos de los otros y asumir obligaciones en relación con una tarea (de aprendizaje, de capacitación, de convivencia) junto a un grupo de personas. Es decir, la construcción - junto con el adolescente- de un escenario que lo aleje de la transgresión de la norma penal (Relevamiento UNICEF, 2015, p.12).

Estas medidas de carácter cautelar o sancionatorio, pero a la vez teñidas de enunciados basados en lo "socio educativo", tienen como finalidad el sentido de responsabilización del joven y a la vez que contribuyan a su desarrollo como "persona-ciudadano" (Zabaleta, 2020, p. 6).

Más allá de que el marco legal prescribe que se opte por medidas socioeducativas en Argentina el $60 \%$ de los jóvenes y adolescentes (Relevamiento UNICEF, 2015) están, o detenidos en centros cerrados para jóvenes o en prisiones. Cabe señalar que la oferta educativa en estos espacios es escasa o prácticamente nula. Por ejemplo, tal como describe una investigación hecha en un espacio cerrado en la Provincia de Buenos Aires (Zabaleta, 2020) ${ }^{8}$, los jóvenes entrevistados dicen que iban a la escuela "un rato", "algunos días de la semana", "a veces", "de lunes a viernes dos horas", "a veces menos", "a veces una hora", "a veces no".

Esto mismo se repite en relación a la oferta de formación laboral que claramente no existe como tal, sino que son talleres más del orden de lo recreativo, sin recursos ni materiales, con profesores que no asisten, que fragmentan la tarea y se ausentan de sus puestos de trabajo sin contar la institución con reemplazos.

Por el otro lado, el testimonio de un estudiante alojado en un centro cerrado, expone lo que se vive adentro de estos espacios:

\footnotetext{
${ }^{6}$ La Comisión por la Memoria (CPM) es un organismo público autónomo y autárquico que promueve e implementa políticas públicas de memoria y derechos humanos. La CPM creó en 2002 su primer programa de intervención para las violaciones de derechos humanos cometidas en el presente: el Comité contra la Tortura. Es actualmente Mecanismo Local de Prevención de la Tortura de la Provincia de Buenos Aires (Ley Nacional 26.827).

${ }^{7}$ Centros de régimen cerrado: son los dispositivos empleados para aplicar una medida de privación de libertad, impuesta a menores de 18 años de edad, infractores o presuntos infractores de la ley penal, dispuestas por juzgados y tribunales con competencia en la materia. Estos centros cuentan con barreras, alambrados, muros, puertas cerradas y personal de seguridad, a fin de cumplir con las medidas estipuladas. (UNICEF 2008).

8 Testimonios tomados de Zabaleta (2020) cuyo trabajo de investigación se centró en analizar las características que adquiere el Sistema de Responsabilidad Penal Juvenil en la provincia de Buenos Aires y fundamentalmente en los establecimientos de régimen cerrado para el cumplimiento de medidas privativas de la libertad (Centros Cerrados), particularmente en el Centro Cerrado Leopoldo Lugones de la ciudad de Azul, tomando para el análisis el recorte temporal del año 2018.
} 
Estos lugares no sirven. Yo, por ejemplo, si salgo de acá y no tengo una persona que me ayude, yo voy a salir más loco, más golpeado. Más golpeado de la vida ¿entendés? Estos lugares son lo peor. Si vos querés cambiar, vas a cambiar, pero necesitas alguien que te ayude. No es que te encierren y por eso va a cambiar porque este chico estuvo encerrado. De acá salís peor. Tres veces ya cumplí años preso. A veces siento que estoy en un pozo del que no puedo salir, y a veces me dan ganas de hacer cosas que pienso en mi cabeza. Tengo ganas de matarme. No es que esté loco, pero yo no te voy a mentir, a veces quiero quitarme la vida. (Joven 10 en Zavaleta, 2020, pp.92-93).

Esto pasó y sigue pasando en las instituciones socioeducativas cerradas destinadas a jóvenes. Los y las jóvenes -aunque mayoritariamente son varonesllegan a este espacio sin educación completa, sin oferta y oportunidades y, en ese contexto, son privados de su libertad. ¿Para qué estar en lugares despojados de recursos, de materiales, de vínculos? En el caso de los centros cerrados incluso se los traslada a muchos kilómetros de sus domicilios. Si hay un vínculo familiar, éste se ve interrumpido, distanciado, lo que genera otra arista al problema ya instalado. Son recurrentes los relatos de personas adultas detenidas en cárceles del Servicio Penitenciario Bonaerense que transitan por las propuestas de la UNICEN cómo su vida escolar se interrumpe en la adolescencia al "caer detenidos $^{\prime \prime 9}$ y no poder darle continuidad en esa detención.

\section{Las instituciones educativas, los docentes y las prácticas}

Volviendo al título de esta presentación, al proponer especular esa mirada, la invitación está dirigida a pensar cuál es la tarea de las instituciones educativas que se localizan al interior de estos espacios. $Y$ pensar también ¿qué pasa con las prácticas educativas de quienes transitamos por esas aulas? Por otro lado, quienes nos ocupamos de la formación de los educadores ¿tenemos como referencia los espacios de detención como espacios laborales?, ¿identificamos esos territorios específicos, advirtiendo la relevancia de la tarea educativa en sentido amplio? Estos interrogantes nos remiten a revisar al menos dos ejes. Por un lado, para analizar las instituciones educativas que se ubican en estos contextos y por otro, pensar las prácticas educativas de los docentes.

Ubicar a las escuelas como objeto de análisis, nos lleva a reconocer las tensiones que las atraviesan y los territorios a disputar, atendiendo a su condición de estar anclada físicamente en un territorio gobernado por otra institución que pretende ser total en términos de Goffman. Se nos hace necesario identificar en las escuelas sus múltiples dimensiones y las condiciones para habitar y desplegar su tarea en un territorio ajeno, atravesado por normas e imposiciones de dominación que desafían y muchas veces obstaculizan alcanzar sus objetivos. Desde este punto de vista, entonces, la primera parada que vamos a hacer es pensar en las instituciones educativas.

\footnotetext{
9 "Estuve hasta 9no grado en la Primaria Rosario Peñaloza, ya de ahí había que cambiarse de escuela porque era sólo primaria. De ahí me dieron una beca por mis notas, para un instituto privado, en 1er año, una beca estatal para hacer el Polimodal ahí, que era en ese momento el plan de estudios. No lo pude terminar, caí detenido ya en primer año, como menor, y así estuve detenido cierta cantidad de veces y no tuve oportunidad de terminarlo". (Fragmento de entrevista. Cristian P. Up7. 2021).
} 
El esquema que se presenta a continuación es una propuesta teórica de referencia para abordar un concepto que ordena la lectura: el de palimpsesto institucional escolar (Umpierrez 2017)

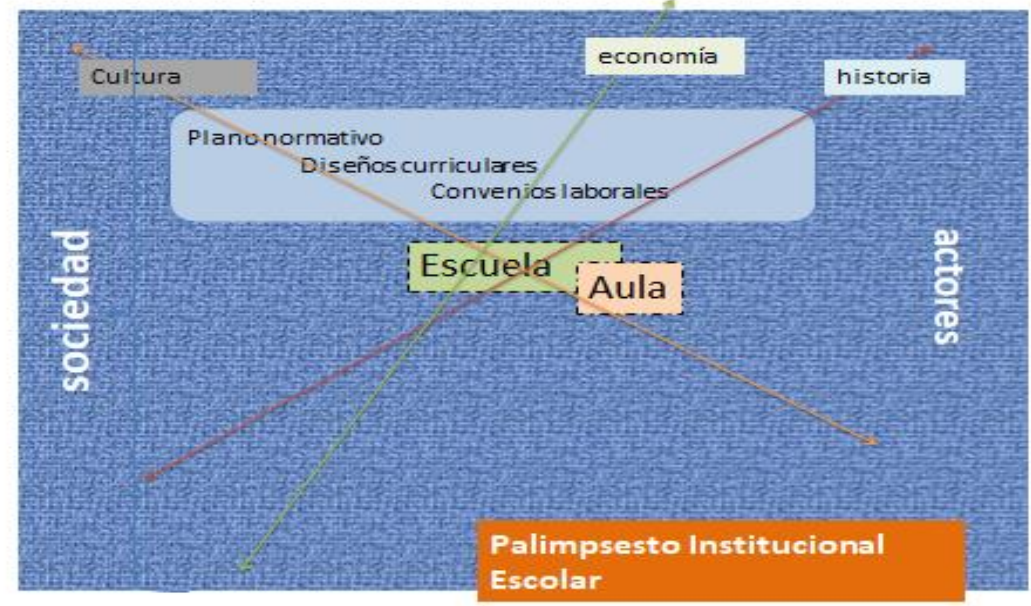

Figura 1- Palimpsesto institucional escolar

¿Qué es un palimpsesto? los pergaminos en el Antiguo Egipto se escribían y se borraban para poder volver a ser escritos. Pero, en ese borrar dejaban su huella y, en la escritura nueva esa huella volvía a emerger.

Los palimpsestos institucionales escolares dan cuenta de las sucesivas capas de la historia sedimentadas de la vida cotidiana de las escuelas (Rockwell y Ezpeleta, 1983) en las que se materializan prescripciones estatales y de las corrientes pedagógicas preponderantes, que se actúan en las escuelas concretas interpretándolas, redefiniéndolas, dando cuenta de resistencias, asignaciones de nuevos sentidos y significados. Se ponen en juego en estas relaciones las imágenes visionadas de los fundadores de estas escuelas y el proyecto sociopolítico del Estado en el contexto en el que se da su surgimiento, como espacio históricamente vivido (en su conformación histórica y sus actualizaciones en el presente), porque ambas son re-presentadas por los actores. El supuesto sobre el que se construye esta categoría es que los imaginarios que se sostienen sobre las instituciones, a los que reconocemos como un sistema de relaciones, inciden en la conformación y desempeño institucional de las escuelas. Es una clave de lectura que permite penetrar la densidad de las imágenes condensadas superpuestas, sedimentadas históricamente, que se activan en la vida cotidiana de las instituciones, que convierten en "naturales" y legitiman prácticas que devienen en inclusiones y exclusiones. $Y$ esas sucesivas capas sedimentadas se actualizan y resignifican presentificándose y actuando mandatos y sentidos fundacionales.

Este punto de mirada nos interpela respecto de las escuelas que desarrollan sus tareas en instituciones que alojan adolescentes y jóvenes alcanzados por la cadena punitiva desde el proyecto sociopolítico del Estado y el mandato -aquel que es público y el oculto- que acompañó su fundación. Cabe interrogar entonces, cómo cada escuela asume, las maneras en que interpreta e implementa las prescripciones oficiales, los destinos trazados de antemano para su población destinataria, adentrándonos en el análisis de qué prioriza, qué 
resiste, qué niega. Y, además, interrogarnos acerca de cuáles son los límites y las oportunidades de fisura, de penetrar capilarmente a un sistema como el de la detención, que se menciona como de "la crueldad" según definen los informes del Comité Contra la Tortura de la Provincia de Buenos Aires, contradiciendo las normas que amparan y protegen la niñez y adolescencia.

Esto nos lleva al segundo plano de revisión de esa mirada: las prácticas educativas. Poner el análisis en este eje es reconocer que implica en múltiples formas no solo a quien desarrolla la tarea en el aula y más allá de ella, sino también a sus estudiantes y nos demanda atender algunos interrogantes en vistas a nuestro recorrido. Por un lado, la pregunta que surge es quién educa al educador. La formación de docentes es un tópico central para entender que son las prácticas de actores situados - maestros y profesores- los que llevan adelante la tarea en el territorio: ¿de qué modo se prepara a quienes habrán de llevar adelante la tarea en estos territorios? ¿Qué aspectos de la formación de grado y a lo largo de su tarea como trabajador de la educación debería fortalecerse? Y como contracara, preguntarse qué pasa en la escolaridad y el encuentro en el aula con los y las jóvenes en reclusión. Estas dos caras de la misma moneda nos convocan a pensar la enseñanza y la formación de quienes trabajamos en contextos de privación de libertad desde el campo educativo.

Una de las consideraciones centrales es reconocer que son escasas las trayectorias formativas en las carreras de formación docente que buscan dar herramientas que permitan a maestros y profesores ser productores de conocimiento, es decir habilitar y promover la convicción de que la reflexividad sobre los procesos de trabajo genera conocimiento que merece darse a conocer. Por tanto, ofrecer herramientas que conduzcan a sistematizar, analizar y aportar al campo pedagógico nuevos conocimientos como resultado de sus prácticas es una vertiente que hay que explorar y fortalecer.

La investigación educativa que se produce desde la propia práctica es una clave de recuperación de la propiedad del trabajo de los docentes, de su condición de constructores y sabedores. No somos los investigadores de la universidad los únicos que podríamos estar aportando saber a este campo, que es muy vasto y complejo.

Por otro lado, les propongo pensar la intervención que hacemos los docentes. Aquí me parece que hay líneas específicas que nos ponen a pensar en tensiones que desafían las perspectivas de la didáctica tradicional, la didáctica más prescriptiva y técnico-instrumental respecto de perspectivas críticas.

Las tareas docentes comprenden responsabilidades asumidas con el cargo respecto de las prescripciones del Estado en función de los contenidos previstos en los diseños curriculares y las funciones prescriptas para cada puesto de trabajo. Poniendo ahora la mirada en quien aprende, la tarea en contextos de privación de libertad ambulatoria nos ha expuesto que los estudiantes de estos espacios son mucho más proclives a buscar conexiones entre el contenido que se enseña con sus experiencias vitales.

La posibilidad de ofrecer propuestas que articulen aquello que se debe enseñar por prescripción curricular con los intereses de los y las estudiantes ofrece una oportunidad para conformar un currículum entendido como construcción compartida de significados (Porlán, 1997). 
Por tanto, es una estrategia que aportaría a un proceso de transformación educativa, formar docentes que intencionalmente y de modo colegiado puedan conformarse en investigadores de su práctica, que puedan acompañar en ese proceso a quienes se inician y que propicien espacios de trabajo en las aulas que apunten a la construcción compartida de conocimientos con sus estudiantes. Esta perspectiva de intervención educativa requiere pensar en problemas de enseñanza y no solo en el contenido de las disciplinas.

En este punto y yendo a un nivel más profundo de reflexividad sobre nuestra tarea, vale interrogarnos no solo sobre qué supuestos nos constituyen como educadores que desarrollamos prácticas educativas en contextos de privación de libertad respecto de que enseñar, a quiénes y cómo, sino además revisar la perspectiva ético política que sostiene nuestras prácticas como convicción más profunda.

Nada puede transformarse sin una plataforma que parta de concebir a la educación centrada en los derechos humanos, una educación que se niegue a reproducir condiciones de dominación que el neoliberalismo impone y que apunte a formar ciudadanos plenos. ¿De qué modo? Se trata de habilitar espacios formativos que ofrezcan herramientas para poder usar la voz, la palabra y la acción para transformar un mundo cada vez más excluyente en un lugar con más derechos para toda la ciudadanía (Uranga, 2012). Esta tarea conlleva a que no solo veamos a los docentes como responsables en las aulas, sino también a los procesos que se despliegan entorno de la puesta en acto de sus prácticas educativas que involucran a las instituciones estatales y a la comunidad toda.

Las prácticas educativas no están centradas exclusivamente en la enseñanza frente al aula, sino que la exceden, incluye a la escuela y se extiende a procesos pedagógicos con la comunidad, para la comunidad, desde la comunidad. Creo que estas son discusiones que, en nuestro país, en términos discursivos ya están muy claras, pero no necesariamente se están teniendo en cuenta a la vista en términos operativos y concretos. ¿Por qué digo esto? Vuelvo para atrás un segundo. Cuando pienso en el marco legal, y estoy pensando ahora a la vez en esa escuela adentro de este Centro Cerrado en clave topológica, y allí los chicos dicen "a mí no me llevan a la escuela", puede ser que la escuela no tenga posibilidad de debatirle al responsable de la gestión del Centro que deje salir a ese chico. Pero tal vez la escuela tiene espacios para generar movimientos para que ese servicio cumpla con su tarea y no está ocupando ese espacio para tensionar los límites que imponen quienes gobiernan la institución de encierro. Desde el plano normativo la ley de protección de derechos de niños, niñas y adolescentes es desatendida por quienes son responsables del cuidado de quienes están bajo custodia del Estado, y la escuela y sus actores deberían encontrar los modos de hacer que esos derechos sean alcanzados. Son planos interesantes para poner en juego.

Entonces, si nosotros pensamos que la perspectiva de intervención en el aula o en la escuela tendría que estar más centrada en procesos investigativos, pero, además proponiendo articulaciones posibles entre los intereses de los estudiantes y entre aquello que tenemos como representantes del Estado la responsabilidad de garantizar que vamos a enseñar, podemos construir un currículum más ajustado a las necesidades, pero además con sentido para quienes participamos. $Y$, estos sentidos, además, deberían estar en conexión con 
intereses y problemas sociales concretos de intervención social, medioambientales, entre otros. En el caso de las personas jóvenes que están bajo la custodia del Estado a mi entender, a lo mejor, se trata de trabajar sobre qué es lo que los llevó a estar en ese lugar, cómo re-articularse y cómo pensar y pensarse para el momento en que recuperen la libertad. Es decir, la educación no debería sólo enfocarse en la trasmisión de cierto saber acumulado, claramente de interés social, sino que además tiene que tener sentido para estos sujetos, estos jóvenes, estos adolescentes, en términos de encontrar que ahí, además, se actualiza su condición de ser humano, la recupera, tal vez en muchos casos con muy pocas posibilidades de haber alcanzado antes de la detención, la oportunidad de acceder al derecho a la educación.

También se presenta como relevante -y me parece que esto es central- el reconocernos a nosotros mismos como sujetos socio-históricos. Aquí es donde conecto con el cuadro anterior (figura 1), nosotros nos estamos interrogando sobre esas ideas que la formación y nuestra propia trayectoria vital, nuestra trayectoria social hizo de nosotros. ¿Cuánto se juega acá mi condición de clase, mi condición de género, mi condición de etnia? ¿Cómo miro al otro? ¿Qué le asigno? ¿Con qué cuestiones crecí? Si soy capaz de reconocer en mí el machismo, si soy capaz de reconocer en mí el racismo, si soy capaz de reconocer en mí el clasismo, estoy un poco más cerca de pensar la enseñanza desde la perspectiva de los derechos humanos.

Desde la experiencia puedo señalar que el trabajo docente en el contexto de privación de libertad nos somete a situaciones críticas y difíciles, extremas, explícitas. La violencia es explícita. Pero es similar a trabajar con sectores sociales marginalizados y con sus derechos vulnerados históricamente. Entonces, aquí se pone en juego (y mucho) de qué supuestos, qué cargas socio-históricas traigo como ser humano. $Y$, cómo soy capaz de revisar y de atender esta construcción y entender que es mi subjetividad la que entra en juego también cuando entro a trabajar en estos espacios.

Además, poder pensar cuál es la perspectiva desde la que me paro. Aquí, digamos, la perspectiva de derechos es clave, es bastante sencillo clamarla, decirla, pero no siempre es fácil sostenerla. Porque, los contextos educativos dentro de contextos de encierro tienen un doble juego que es que nosotros transitamos el territorio de otros. Entonces, ese territorio de otros, que tiene la llave material y simbólica muchas veces nos pone a prueba en cuán convencidos estamos, que estamos aquí para velar o, al menos denunciar la violación de derechos humanos que suceden en los espacios de privación de libertad.

Me parece que una pregunta que nos tenemos que hacer como educadores puntualmente es, y acá sacaría lo de contexto de privación de libertad, lo pondría entre paréntesis, porque si bien ese es nuestro objetivo aquí, me parece que es una pregunta que nos atraviesa en todos los contextos, ¿es posible pensar a la educación como liberadora?

Lo particular de este es esto que les planteaba, lo que vemos es que en estos espacios y de modo descarnado se exhibe la violencia. Tenía otros testimonios que no elegí mostrar, como por ejemplo que, en estos centros cerrados a los jóvenes, a los adolescentes, no les dejan usar calzado cerrado, con cordones, entonces andan en ojotas y en invierno aquí hacen temperaturas bajo cero grados. Son lugares donde no les permiten tener pertenencias propias, 0 
sea que la celda es pequeña y con apenas una ventana de barrotes muy alta, que no permite ver el exterior. Permanecen allí la mayor parte del tiempo, sin nada personal ahí adentro. No hay libros, cuadernos, entretenimiento, visitas. Un adolescente en crecimiento, una persona que debería explorar, expandir, dialogar, discutir, intercambiar, ser amado, ser contenido. Reitero entonces la pregunta, al pensar la educación en ese contexto, ¿es posible de ser pensada como una educación liberadora?

Más allá de las restricciones materiales, no podemos renunciar a pensar que la educación debe venir a liberar el pensamiento, a generar espacios de oportunidad, espacios de reconstrucción de uno mismo -porque esto sí lo vemos, en nuestro trabajo en adultos-. Este transitar por las ofertas de la universidad, la decisión de estudiar, la decisión de ser otro sujeto, la decisión de reconsiderar aquellas cosas que venía pensando. Ayer mismo, un estudiante que hoy está en una unidad penal distante a las que trabajamos, nos escribía diciendo:

Hace unos días aprobé unas materias, las primeras en esta Facultad, pero mi corazón todavía está allá, en el Centro Universitario, es mi lugar, donde comencé a leer libros y donde adquirí valores que no se si no los tenía, pero que en ese lugar los volví a encontrar, no voy a dejar de agradecer nunca a ustedes lo que hicieron por mí que fue abrirme las puertas de la Universidad y haberme tratado como lo hicieron, el acompañamiento y todo lo demás. Acá hace poco hubo un motín seguramente deben saberlo, quería hacerle hincapié en eso es más estuve pensando en estos días hacerle una carta para ustedes tanto a compañeros como a todos los que forman parte del proyecto. (Leandro, comunicación personal, diciembre 2020) $)^{10}$.

Entonces, me parece que no es una utopía. Es un horizonte sobre el que hay que trabajar, pero claramente no es una tarea individual, sino que es una tarea colegiada, colectiva, es una tarea que requiere que intervengamos en la definición y en el impulso de las políticas públicas que están. Es decir, puede haber un marco legal estatal que nos ampare, pero es en el ámbito escolar, en el plano institucional, en el ámbito del aula, donde nosotros tenemos que velar para que ese marco se cumpla.

Si los jóvenes en contexto de encierro deben ser orientados hacia prácticas socioeducativas y la razón de estar ahí son las prácticas socioeducativas ¿por qué no se cumple?, ¿cómo vamos a hacer que se eso se cumpla? Muchas de las cuestiones que suceden en estos espacios suceden también porque los docentes nos sometemos, no problematizamos un discurso que, como el palimpsesto, quedó instalado respecto de que estos jóvenes ya no tienen oportunidades, no tienen salida, no hay futuro para ellos, por lo tanto, lo que se educa aquí es para seguir repitiendo algo que no debería ser: la violencia, la violación de la ley, el deseo de matar o matarse. Esa es la dimensión en la que tenemos que trabajar.

${ }^{10}$ Se trata de un joven de alrededor de treinta años que pasó por uno de los Centros Universitarios en los que trabajamos en el año 2017. Hace referencia a la represión e incendio de Centros Universitarios de manos del Servicio Penitenciario Bonaerense en el mes de octubre del año 2020. 


\section{CONCLUSIÓN}

¿Es posible pensar a los contextos de privación de libertad como espacios de educación liberadora, que forme ciudadanos y trabajadores críticos?, ¿qué tensiones atraviesan las instituciones educativas en contextos de privación de libertad?, ¿y a las prácticas educativas?, ¿qué lecturas podemos hacer para diseñar caminos de intervención para la transformación de estos espacios que suponen atención a necesidades educativas, laborales y ciudadanas de los y las adolescentes en conflicto con la ley? Son muchos interrogantes a los que habrá de revisar y construir alternativas de acción. Muchas seguramente estarán en camino.

El constructo teórico al que apelamos, el palimpsesto institucional escolar se ofrece como una clave de lectura que permite penetrar la densidad de las imágenes condensadas superpuestas, sedimentadas históricamente, que se activan en la vida cotidiana de las instituciones, que convierten en "naturales" y legitiman prácticas que devienen en inclusiones y exclusiones. $Y$ esas sucesivas capas sedimentadas se actualizan y resignifican presentificándose y actuando mandatos y sentidos fundacionales. Sólo la posibilidad de reflexividad que permita el análisis y la comprensión de esta densa construcción socio-histórica de significados sedimentados y compartidos en los imaginarios sociales puede habilitar espacios de disputa y resistencia a ese "destino".

La formación de docentes investigadores, productores de conocimiento a partir de sus prácticas fortalecería la relación dentro y fuera del aula en relación a ser autores de sus trabajos, lectores críticos de las instituciones y en ese camino, colectivamente capaces de diseñar espacios que amplíen oportunidades educativas y formativas para el trabajo e incidir en el diseño de políticas públicas y en las políticas educativas en particular. No se trata tanto de sumar o restar líneas en los diseños curriculares sino en revisar los modos en que concebimos y desplegamos las tareas de las escuelas y de las prácticas educativas. El entrecruce de la institución de privación de libertad y la tarea de educar a jóvenes vulnerabilizados, demanda enlazar instituciones, educadores y estudiantes en clave de derechos humanos.

\section{REFERENCIAS}

Daroqui, A. y López, A. L. (2012). La cadena punitiva: actores, discursos y prácticas enlazadas en A. Daroqui, A. L. Lopéz y R. Cipriano García (2012) Sujeto de castigos. Hacia una sociología de la penalidad juvenil. Homo Sapiens CPM.

Fondo de las Naciones Unidas para la Infancia y Secretaría Nacional de Niñez, Adolescencia y Familia (2008) Adolescentes en el Sistema Penal. Situación actual y propuestas para un proceso de transformación. Ministerio de Desarrollo Social.

Informe Anual (2019). El Sistema de la Crueldad XIII Sobre lugares de encierro, políticas de seguridad, salud mental y niñez en la provincia de Buenos Aires Comisión Provincial por la Memoria. https://www.comisionporlamemoria.org 
Motto, C. y López, A. (2017). Baja de edad de punibilidad, el diagnóstico inexistente: estadísticas e indicadores sobre la cuestión penal juvenil. Ponencia. XII Jornadas de Sociología. UBA. http://jornadasdesociologia2017.sociales.uba.ar

Porlan, R. (1997). Constructivismo y escuela: hacia un modelo de enseñanzaaprendizaje basado en la investigación. Díada Editora, S.L.

UNICEF-CENAF (2015). Relevamiento nacional sobre adolescentes en conflicto con la ley penal. Año 2015 Secretaría Nacional de Niñez, Adolescencia y Familia (SENAF) Fondo de las Naciones Unidas para la Infancia (UNICEF).

Rockwell, E. y Ezpeleta, J. (1998 [1983]). La escuela, relato de un proceso de construcción inconcluso. Revista Novedades Educativas (95).

Salgado, V. y Fridman, D. (2015). El derecho a la educación en la Argentina a 25 años de la ratificación de la Convención sobre los Derechos del Niño: logros y desafíos pendientes para su pleno cumplimiento. Campaña Argentina por el derecho a la educación. http://observatoriojovenesiigg.sociales.uba.ar/

Umpierrez, A. (2009). El acceso a una carrera universitaria de profesorado en una universidad regional: entre elecciones y oportunidades de un campo ocupacional, determinaciones y autonomías, sujetos y contextos. Tesis de Maestría. Facultad de Ciencias Humanas, UNICEN. Inédita.

(2016). La Universidad entra a la cárcel, la cárcel entra a la Universidad. Fermentario 1(10) 1-15.

(2017). Obligadas a obligar: Las escuelas secundarias, vórtices de la escolaridad obligatoria en una ciudad de rango intermedio. Repositorio de la Facultad de Filosofía y Letras. http://repositorio.filo.uba.ar/

(2020). Aulas y estudiantes universitarios organizados en la cárcel: un territorio en tensión. Educação e Cultura Contemporânea 1入48) 81-103. http://periodicos.estacio.br

Uranga, W. (2013). Comunicación: en la encrucijada de la construcción ciudadana. Revista Intersecciones en Comunicación 71 1) 11-39.

Zabaleta, D. (2020) Encierro juvenil: Dinámica, materialización y significado de la pena de encierro. Un estudio de caso en el Centro Cerrado Leopoldo Lugones Tesis para obtener el grado de Licenciatura. Facultad de Ciencias Humanas, UNICEN. Inédito. 